\title{
Design and Measurement of Novel Shaped Microstrip Antenna with DGS for Radar Applications
}

\author{
R. Kiruthika ${ }^{\mathrm{a}}$, T. Shanmuganantham ${ }^{\mathrm{b} *}$ \\ ${ }^{a}$ M.Tech, Dept. of Electronics Engg., Pondicherry University, Puducherry - 605 014, India \\ ${ }^{b}$ Asst. Prof., Dept. of Electronics Engg., Pondicherry University, Puducherry - 605 014, India
}

Received: 10 November 2017; Accepted: 13 February 2018; Published: 08 May 2018

\begin{abstract}
In this paper, a novel shaped patch antenna for triple band frequency of operation in X-band (radar) is defined. The antenna resonates under three frequency bands at $10 \mathrm{GHz}, 10.93 \mathrm{GHz}$ and $11.68 \mathrm{GHz}$ respectively which are included in the X-band frequency range. The substrate material used as the dielectric between the patch and the ground is of Flame Retardant Version 4 (FR4) Epoxy. The DGS (Defected Ground Structure), usually included in the back conductor of the Microstrip patch antenna is used to tune the frequency and also to boost the characteristics of the antenna. The same is included in this depicted antenna with circular ring shaped slot to vary the performance. FEM (Finite Element Method) based Ansoft High Frequency Structural Simulator (HFSS) V.12 is used for designing and verifying the features of the proposed antenna. The size of the depicted model on the whole is of $31.34 \times 28.33 \times 1.6 \mathrm{~mm}^{3}$. For the first, second and third resonant frequency, a bandwidth of $480 \mathrm{MHz}, 600 \mathrm{MHz}$ and $420 \mathrm{MHz}$ correspondingly is obtained with a return loss value of $-18.47 \mathrm{~dB},-42.22 \mathrm{~dB}$ and $-19.74 \mathrm{~dB}$. The other parameters of the antenna are also conferred in this paper.
\end{abstract}

Index Terms: Defected Ground Structure; FR4 Epoxy; bandwidth; return loss.

(C) 2018 Published by MECS Publisher. Selection and/or peer review under responsibility of the Research Association of Modern Education and Computer Science

\section{Introduction}

Nowadays, wireless communication has been employed in most of the applications. For those devices, antenna plays an important role at its end terminal. The main role of the antenna is to transfer the Radio Frequency signal into electromagnetic wave in free space and vice versa due to its reciprocity. Microstrip patch

*Corresponding author. Tel.: 9486640168

E-mail address: shanmugananthamster@gmail.com 
antenna is such a type of antenna and is used in most of the wireless applications because of its smaller size, low profile characteristics, etc,. They are of mechanically stiff plane, less weight, have the capability of low expenditure and easy manufacturing characteristics with printed circuit technology [1]. Few applications of Microstrip antenna are of radar, satellite, MMIC, mobile handset etc [6]. The performance of an antenna can be improved by providing stacked structure [16]. In turn, the size of the antenna is generally of larger value when designed for low frequency applications. But miniaturization is important for portable wireless applications. This can be achieved by providing slots on the patch [8] [14] or by using the fractal shaped structures as the patch itself [15]. The antenna is usually designed to resonate under single frequency band. But with the inclusion of slot in the patch and ground plane, there will be a better improvement in performance with multiband frequency of operation. There are various methods used to introduce slots on the patch such as H-slot [4], C-slot [3], U-slot, and with all these in a combination with parasitic strips adjacent to the radiating patch.

DGS, abbreviated as Defected Ground Structure is an intentional non-periodic or periodic fractal shape or defect added in the conducting ground plane for a purpose of either tuning the frequency or to enable miniaturization of the antenna size [7]. Defected Ground Structure also provides band notch characteristics in an antenna [2]. The LPF (Low Pass filter) [10] and other filters [9] can be manipulated and adjusted using DGS provided in the ground plane. Various shapes are available for DGS to be provided in the ground plane such as arrow headed DGS, polygonal, concentric ring slot, open loop square, etc [5].

The second section gives a brief detail about designing the depicted antenna model with its parameter value calculation for each and every dimension included. The results obtained for the designed model is given under the third section with gain, VSWR (Voltage Standing Wave Ratio), directivity and current distribution for all of the three resonant frequencies. Also the simulated and measured comparison of return loss value is given under the same section.

\section{Design Configuration}

In this section, the design consideration and the parameters of the depicted design model is conferred. A grouping of conventional shapes like rectangular and circular, with slots included in it forms the radiating patch above the substrate. The FR4 substrate that has a loss tangent value of 0.02 and relative permittivity $\left(\varepsilon_{\mathrm{r}}\right)$ of 4.4 has a conducting ground plane below which includes a circular ring slot in order to provide additional tuning frequency. The entire size of the antenna is of $31.34 \times 28.33 \times 1.6 \mathrm{~mm}^{3}$ as width, length and height respectively. The FR4 dielectric substrate has a height or thickness (h) of $1.6 \mathrm{~mm}$.

The conventional formulas given under (1-7) are used to calculate each of the magnitude of the depicted model and is given below:

$$
\begin{aligned}
& W=\frac{C_{O}}{2 f_{r}} \sqrt{\frac{2}{\varepsilon_{r}+1}} \\
& \varepsilon_{r e f f}=\frac{\varepsilon_{r}+1}{2}+\frac{\varepsilon_{r}-1}{2}\left(1+\frac{12 h}{W}\right)^{-\frac{1}{2}} ; \frac{W}{h}>1 \\
& \frac{\Delta L}{h}=0.412 \frac{\left(\varepsilon_{r e f f}+0.3\right)\left(\frac{W}{h}+0.264\right)}{\left(\varepsilon_{r e f f}-0.258\right)\left(\frac{W}{h}+0.8\right)}
\end{aligned}
$$




$$
\begin{aligned}
& L=\frac{C_{O}}{2 f r \sqrt{\varepsilon r e f f}}-2 \Delta L \\
& L_{g}=6 h+L \\
& W_{g}=6 h+W \\
& a_{e}=\frac{1.8412 c}{2 \pi f_{r} \sqrt{\varepsilon_{r}}}
\end{aligned}
$$

The formula (1-4) is used for Width (W) and Length (L) calculation of rectangular patch and for the slots used in the design. Equation (5-6) is used to define the breadth $\left(\mathrm{W}_{\mathrm{g}}\right)$ and Length $\left(\mathrm{L}_{\mathrm{g}}\right)$ of the conducting ground plane. The final equation is used to calculate the radius $\left(a_{e}\right)$ of the circle for a given resonant frequency $\left(\mathrm{f}_{\mathrm{r}}\right) . \varepsilon_{\text {reff }}$ denotes the effective dielectric constant of the material.

\subsection{Design parameters}

As mentioned earlier, the designed top and bottom view of the depicted antenna model simulated using Ansoft HFSS (High Frequency Structural Simulator) V.12 is given below in Fig. 1. The excitation provided is by means of Microstrip line Feeding Technique [11].

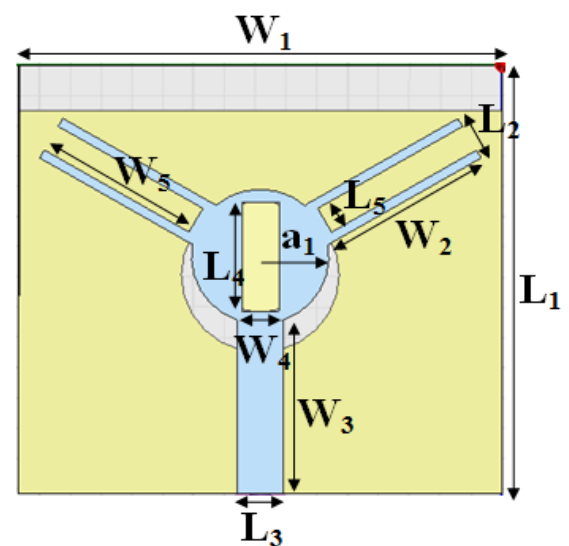

(a)

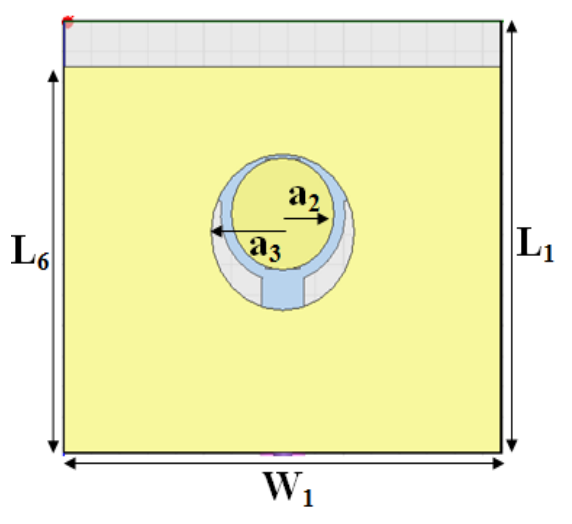

(b)

Fig.1. Proposed design model (a) view at front (b) view from bottom

Table 1 illustrates the value of each of the parameters included in the design model that have been calculated using the conventional formula (1-7) as referred from the literature survey [13][12]. 
Table 1. Design Parameters of the depicted antenna model

\begin{tabular}{ccccccccccccc}
\hline Parameters & $\mathrm{L}_{1}$ & $\mathrm{~W}_{1}$ & $\mathrm{~L}_{2}, \mathrm{~L}_{3}$ & $\mathrm{~W}_{2}, \mathrm{~W}_{3}$ & $\mathrm{~L}_{4}$ & $\mathrm{~W}_{4}$ & $\mathrm{~L}_{5}$ & $\mathrm{~W}_{5}$ & $\mathrm{~L}_{6}$ & $\mathrm{a}_{1}$ & $\mathrm{a}_{2}$ & $\mathrm{a}_{3}$ \\
\hline Values in $\mathrm{mm}$ & 28.3 & 31.3 & 3.01 & 11.5 & 7.23 & 2.41 & 1.8 & 10.9 & 25.3 & 4.46 & 3.68 & 5.12 \\
\hline
\end{tabular}

For a resonant frequency of $9.1 \mathrm{GHz}$, the dimension of circular and rectangular shapes provided in the radiating patch is calculated. Similarly, the dimension of the shapes or defect provided in the conducting ground plane is formulated for the resonant frequency of $11 \mathrm{GHz}$. Particularly, the length $\mathrm{L}_{1}, \mathrm{~L}_{2}, \mathrm{~L}_{3}, \mathrm{~L}_{4}$ and $\mathrm{L}_{5}$ are calculated based on $9.1 \mathrm{GHz}$ with variation in dimension as a multiples of $\mathrm{L}_{1}$ to obtain an optimized result. The same is done for the widths used in the patch. The DGS $\mathrm{a}_{2}$ and $\mathrm{a}_{3}$ provided in the ground plane are calculated for a centre frequency of $11 \mathrm{GHz}$.

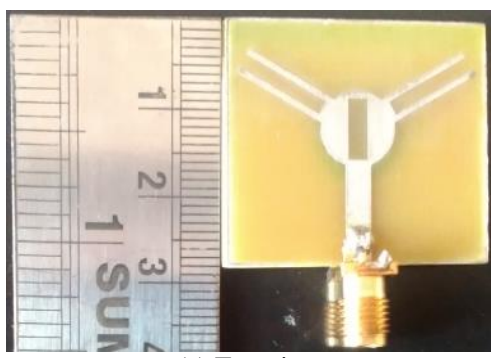

(a) Top view

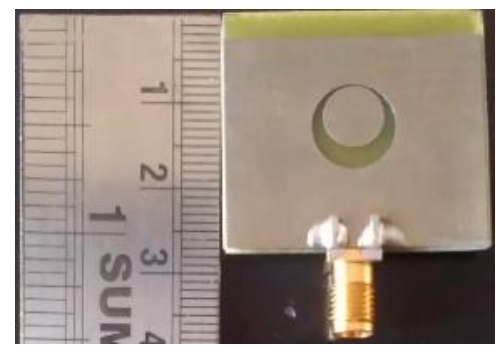

(b) Back view

Fig.2. Prototype of the proposed antenna

\section{Results and Discussion}

The computer-generated and measured characteristics of the depicted antenna structure are conferred. The measurement was done using ZVL Network Analyzer and simulation was performed using Ansoft HFSS V.12 as said earlier. The measured parameters such as return loss and VSWR are given in Fig. 3 and are shown below.

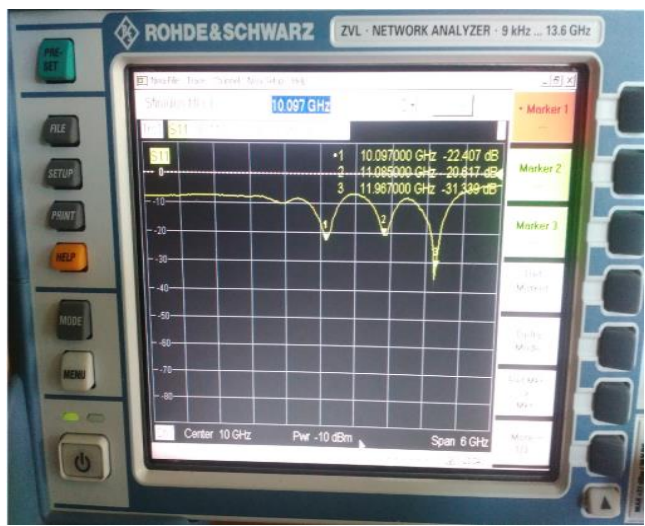

(a) Return loss (dB)

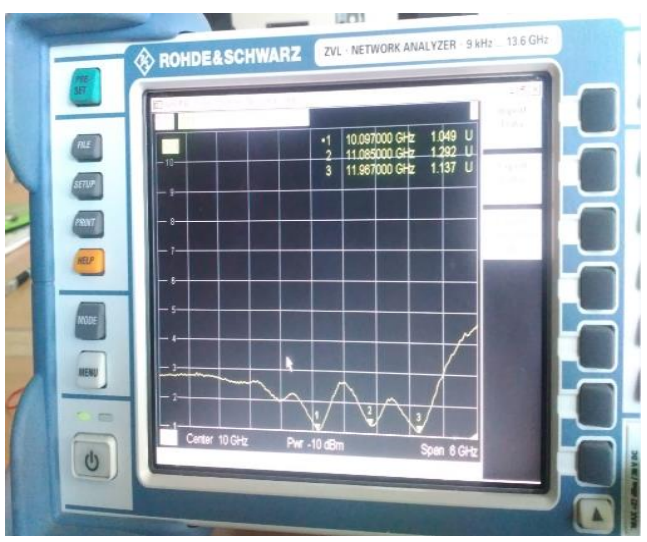

(b) VSWR

Fig.3. Measurement setup of the fabricated antenna 


\subsection{Return Loss}

The comparison of the computer-generated and measured result of the reflection coefficient vs frequency obtained using HFSS v.12 and ZVL Network Analyzer respectively are shown in the Fig. 4. It is clearly inferred from the graph that the antenna resonates under three frequency band with a return loss value of $18.47 \mathrm{~dB},-42.22 \mathrm{~dB}$ and $-19.74 \mathrm{~dB}$ with a bandwidth of $480 \mathrm{MHz}, 600 \mathrm{MHz}$ and $420 \mathrm{MHz}$ for the first, second and third resonant frequency under simulation.

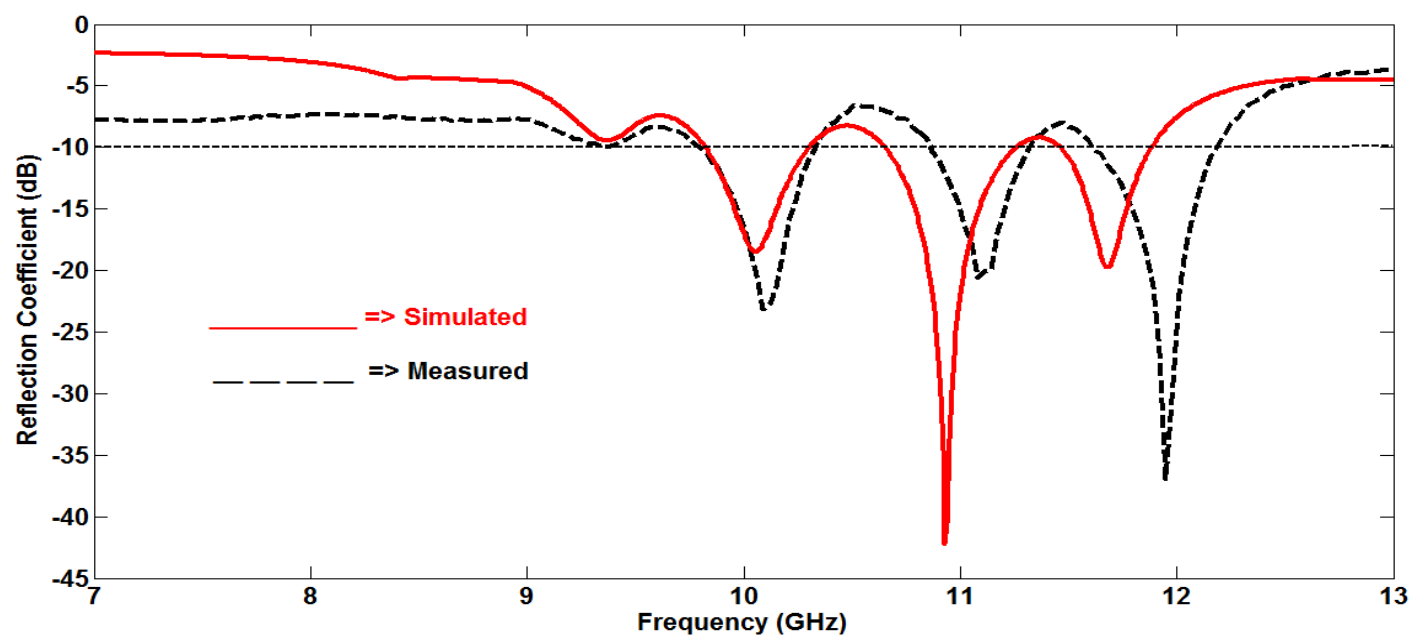

Fig.4. Simulated and Measured result of return loss plot

\subsection{VSWR}

Voltage Standing Wave Ratio (VSWR) is created due to the impedance mismatch at the input terminals. The plot of VSWR vs frequency is given as follows in Fig. 5. The value of VSWR obtained is of 1.15, 1.12 and 1.37 for the first, second and third resonant frequency.

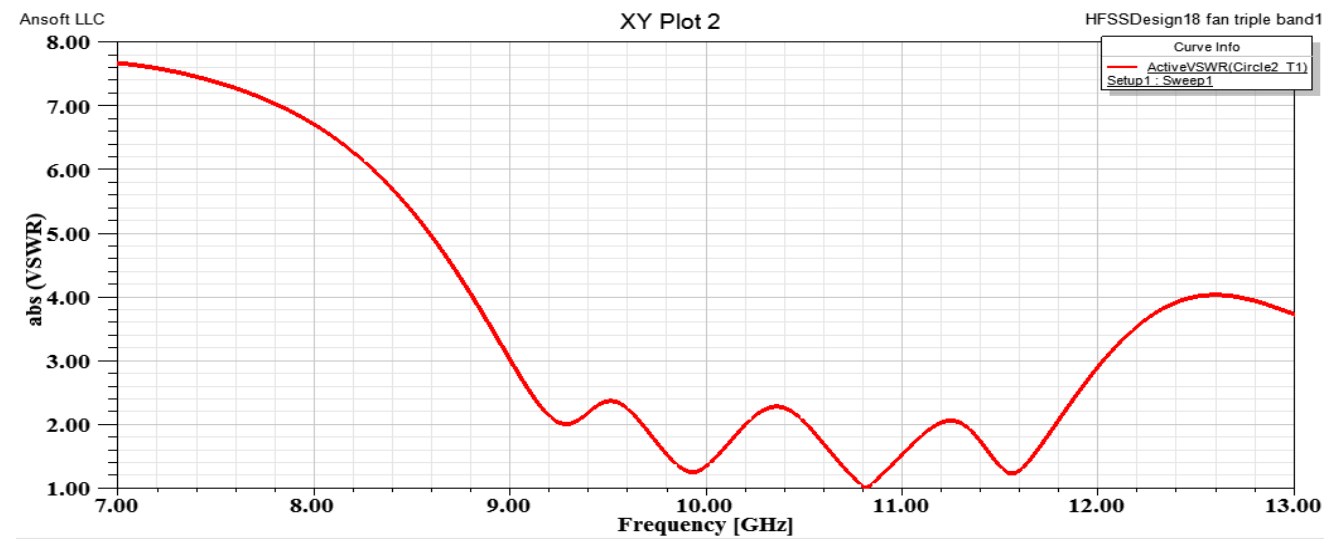

Fig.5. VSWR vs Frequency $(\mathrm{GHz})$ graph of the proposed model 


\subsection{Other Parameters}

Gain and directivity is another important parameter of an antenna. The 3D polar plot of total gain and directivity obtained in terms of $\mathrm{dB}$ is shown in Fig. 6 for three of the resonant frequencies. An overall gain of $3.33 \mathrm{dBi}, 2.91 \mathrm{dBi}$ and $1.17 \mathrm{dBi}$ with a directivity of $5.56 \mathrm{~dB}, 4.94 \mathrm{~dB}$ and $4.75 \mathrm{~dB}$ is obtained for the first, second and third resonant frequency respectively.
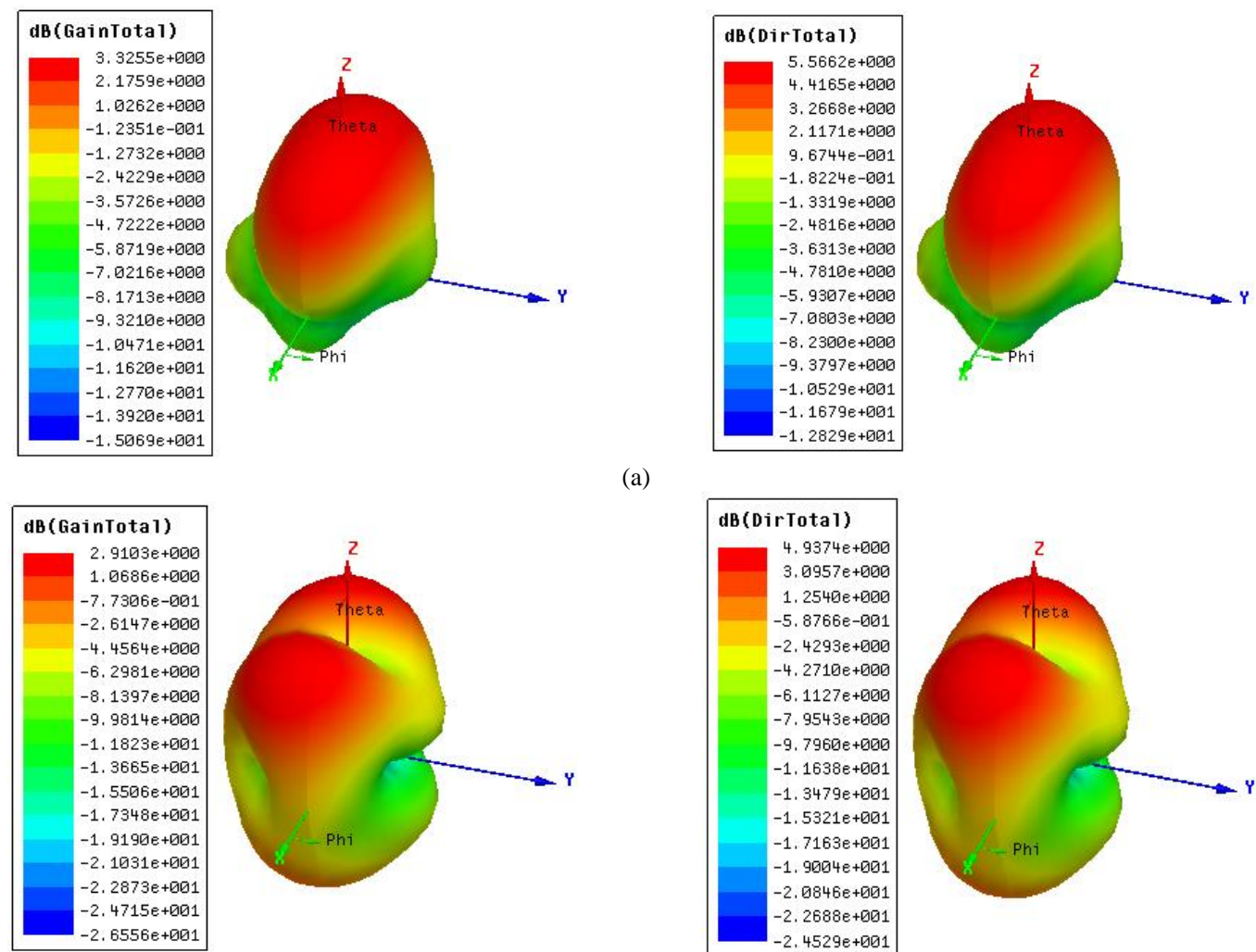

(a)

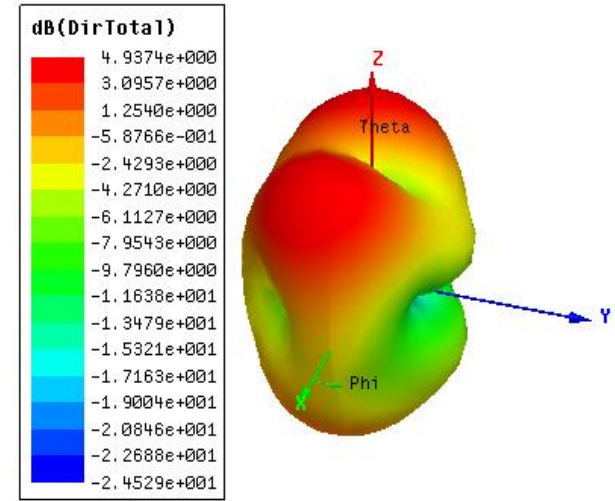

(b)
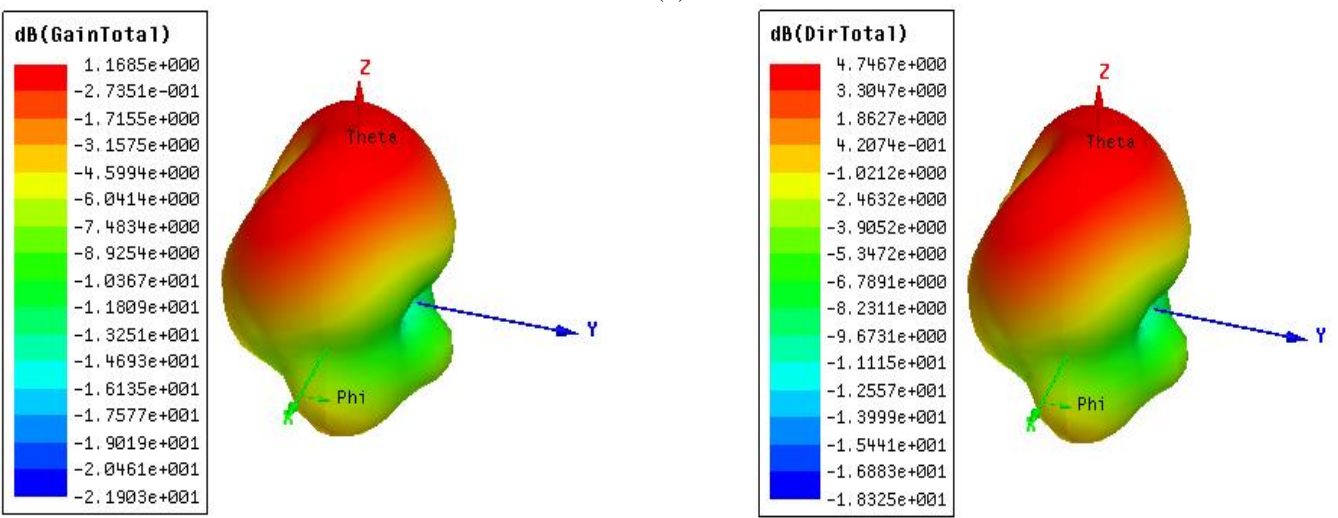

(c)

Fig.6. 3D gain and directivity plot at (a) $10 \mathrm{GHz}$, (b) $10.93 \mathrm{GHz}$, (c) $11.68 \mathrm{GHz}$ 
The radiation characteristics of an antenna for a particular resonant frequency can be easily identified from its surface current distribution. The fringing field produced is along the edges than at the centre of the radiating patch for all of the resonant frequencies.

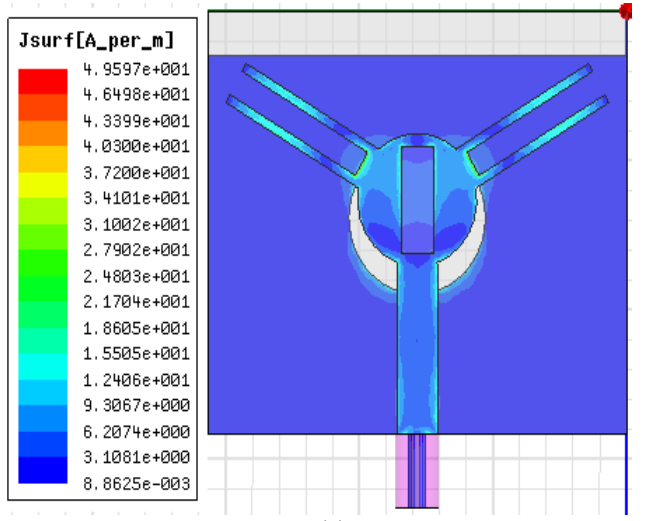

(a)

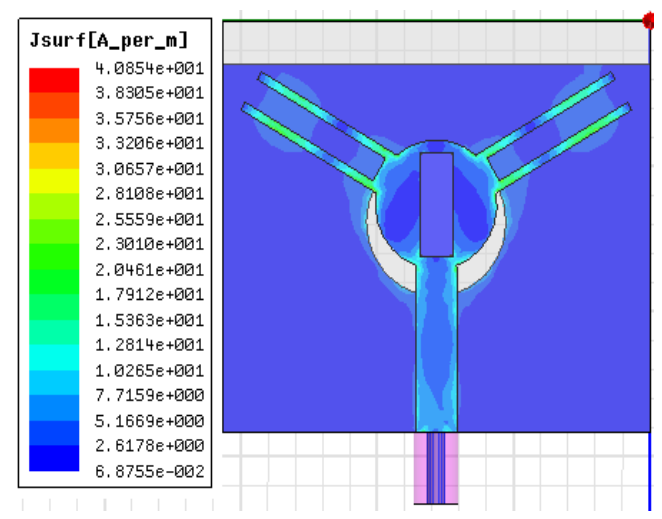

(b)

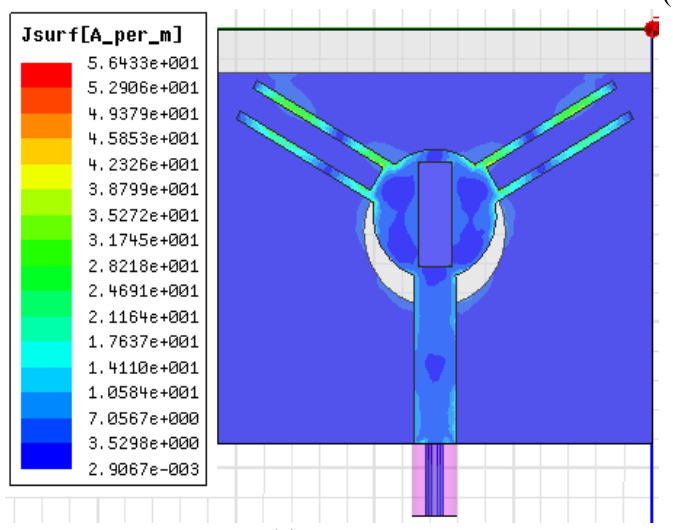

(c)

Fig.7. Current Distribution at (a) $10 \mathrm{GHz}$, (b) $10.93 \mathrm{GHz}$, (c) $11.68 \mathrm{GHz}$

\section{Conclusions}

As described above, the depicted model works well by satisfying all the parameters of an antenna particularly under radar frequency application. The bandwidth obtained is of considerable value and also it is greater than UWB (> $500 \mathrm{MHz}$ ) for the second resonant frequency of $10.93 \mathrm{GHz}$. The measured and simulated reflection coefficient vs frequency matches in a considerable manner with each other. Other characteristics such as Voltage Standing Wave Ratio, gain and directivity are at an optimal level with compact nature of the proposed model.

\section{Acknowledgement}

The authors would like to thank Dr. S. S. Karthikeyan, Indian Institute of Information Technology Design and Manufacturing (IIITDM), Chennai for providing their facilities and infrastructure for testing and measurement of the antenna parameters. 


\section{References}

[1] Ittipiboon, A.; Bhartia, P.; Ramesh Garg; Inder Bahl: Microstrip Antenna Design Handbook, Artech House, 2000.

[2] Itoh, T.; Qian, Y.; Kim, J.; Park, J.S.; Ahn, D.; Kim, C.S.: A design of the LPF (Low Pass Filter) using the novel microstrip Defected Ground Structure (DGS), IEEE Microwave Theory Tech., Vol. 49, no. 1, pp. $86-93,2001$.

[3] Park, S. O.; Kimand, K. H.: Analysis of the small band-rejected antenna with the parasitic strip for UltraWide Band (UWB), IEEE Trans. Antennas Prop., Vol.54, no.6, 2006.

[4] Branch, S. R.: Band-notched elliptical slot UWB (Ultra Wide Band) Microstrip antenna with elliptical stub filled by the H-shaped slot, Journal of EM Waves Appl., Vol. 22, 2008.

[5] Antar, M.M.; Guha, D.: Microstrip \& Printed Antennas New trends, Techniques \& Appls, John Wiley \& Sons, 2011.

[6] Kumar, P.; Singh, G.: Advanced Computational Techniques in Electromagnetic, Article ID ACTE 00110, 2012.

[7] Biswarup Rana; Sarkar, P.P.; Achintya Das; Mrinmoy Chakraborty: Design \& Analysis of Rectangular Microstrip Antenna with slots using DGS (Defected Ground Structure), Procedia Technology 4, Elsevier, 411-416, 2012.

[8] Virdee, B.S.; Sedghi, T.; Aribi, T.; Naser-Moghadasi, M.; Fakheri, M., Sadeghzadeh, R.A.: Miniature Hook-Shaped Multiband Antenna for Mobile Applications, IEEE Antennas \& Wireless Prop. Lett., Vol. 11, 2012.

[9] Raghuvir Tomar; Pragya Singh: The use of Defected Ground Structures (DGS) in designing Microstrip filters with enhanced performance characteristics, Elsevier, Procedia Technology 17, 58-64, 2014.

[10] Ying Yu; Haihand Fu: A Novel Lowpass Filter Based on Multistage Defected Ground Structure (DGS), IEEE International Conference on Ubiquitous Wireless Broadband, 2016.

[11] Kiruthika, R.; Shanmuganantham, T.: Comparison of Direct Contact Feeding Techniques for Rectangular Microstrip Patch Antenna for X-Band Applications, International Journal of Computer Science and Information Security (IJCSIS), CIC 2016, vol.14, 2016.

[12] Prabhakar, D.; Mallikarjuna Rao, P.; Satyanarayana, M.: Design and Performance Analysis of Microstrip Antenna using different Ground Plane Techniques for WLAN Application, International Journal of Wireless and Microwave Technologies(IJWMT), Vol.6, No.4, pp.48-58, 2016.

[13] Sampada C.Deshmukh; Labade, R.P.: On Design of Modified Hexagonal Slot UWB Antenna with Band Notched Characteristics, International Journal of Wireless and Microwave Technologies (IJWMT), Vol.7, No.4, pp.60-70, 2017.

[14] Deepanshu Kaushal; Shanmuganantham. T: Design of Microstrip Trapezoidal Patch Antenna Using Coaxial Feeding Technique for Space Applications, International Journal of Wireless and Microwave Technologies (IJWMT), Vol.7, No.6, pp.1-12, 2017.

[15] Kiruthika, R.; Shanmuganantham, T.: A Canadian Leaf Shaped Triple Band Patch Antenna with DGS for $\mathrm{X}$ and C-Band Applications, World Academy of Science, Engineering and Technology, International Journal of Electronics and Communication Engineering, vol.11, N0.4, 2017.

[16] Deepanshu Kausal; Shanmuganantham, T.: Improved Performance Characteristics Using Double Layer Stacked Microstrip Loop Shaped Patch Structures for X-Band Operation, International Journal of Wireless and Microwave Technologies (IJWMT), vol.8, No.1, pp.14-24, 2018. 


\section{Authors' Profiles}

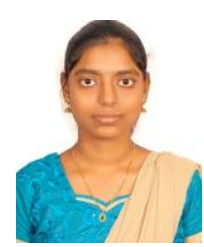

R. Kiruthika received B.Tech. Degree in Electronics \& Communication Engg from Alpha College of Engg \& Technology (affiliated to Pondicherry University) in 2015 and M.Tech. Degree in Electronics and Communication Engineering in the Dept. of Electronics Engg, School of Engg and Technology, Pondicherry Central University, Puducherry in 2017. Research area interest is of Antennas, Microwave/Millimeter-Wave Engineering.

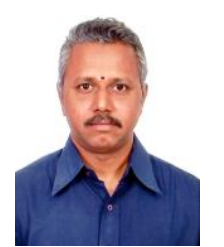

Dr. T. Shanmuganantham was awarded B.E. degree in Electronics \& Communication Engg from University of Madras in 1996, M.E. degree in Communication Systems from Madurai Kamaraj University in 2000 and Ph.D. (Received Gold Medal) in the field of Antennas from NIT (National Institute of Technology), Tiruchirappalli in 2010 under the guidance of Prof. S. Raghavan. He has 21 years of teaching experience in various reputed Engineering Colleges and currently he is working as Asst. Prof. in the Dept of Electronics Engineering, School of Engg \& Technology, Pondicherry Central University, Pondicherry. His research area of interest includes Antennas, Microwave/Millimetre-Wave Engineering, MEMS/NEMS. He has published 450 research papers in various National and International level Journals and Conferences. He has completed two sponsored projects. He has been elected as Fellow in Antenna Test and Measurement Society (ATMS) and a senior member in IEEE, Life Member in ISSS, IETE, IE (India), CSI (India), Society of ISTE, EMC, ILA, OSI and ISI. He is serving as office bearer for IEEE Circuits and Systems Society (India Chapter) and also he is Member of Board of Studies in Pondicherry University, University of Madras, and Annamalai University. His biography was incorporated in 'Marquis who is who in the world' USA in 2010.

How to cite this paper: R. Kiruthika, T. Shanmuganantham," Design and Measurement of Novel Shaped Microstrip Antenna with DGS for Radar Applications", International Journal of Wireless and Microwave Technologies(IJWMT), Vol.8, No.3, pp. 33-41, 2018.DOI: 10.5815/ijwmt.2018.03.04 